\title{
FDA ban of generic oxycodone calls into question Health Canada's approval
}

$\mathrm{H}$ ealth Canada is facing increased criticism for its approval of generic oxycodone after the US Food and Drug Administration (FDA) decided to ban generic versions of the drug that has been widely abused across North America.

The FDA made its landmark ruling just days before Purdue Pharma's patent on the original time-release formula of OxyContin was set to expire Apr. 23.

The original formulations of the drug, including OxyContin and its generic, "poses an increased potential for abuse by certain routes of administration," says Morgan Liscinsky, a spokesperson for the FDA. "The agency has therefore determined that the benefits of original OxyContin no longer outweigh its risks."

In April 2010, the FDA approved OxyNEO as the standard replacement for OxyContin, because the physical and chemical properties of it make it harder to abuse either by injection or snorting.

Despite the FDA's latest decision not to allow the generic version of OxyContin, Health Canada says it has no plans to revisit the issue and is satisfied with its decision, which it says is based purely on scientific evidence.

Federal Health Minister Leona Aglukkaq "chose to not politically interfere and we still believe that that's the right decision because politicians shouldn't be deciding, in our view, which drugs get on the market and which ones don't - that should be based on science," says Steve Outhouse, Aglukkaq's spokesperson.

"Ours is a scientific-based approach that looks at ... whether the benefits outweigh the risks," said Outhouse.

"Our minister felt it was the right approach, and the Americans feel that their approach is the right one," says Outhouse. "Ultimately what's happening here is that all sides agree it's an issue and they're just looking for ways to deal with it."

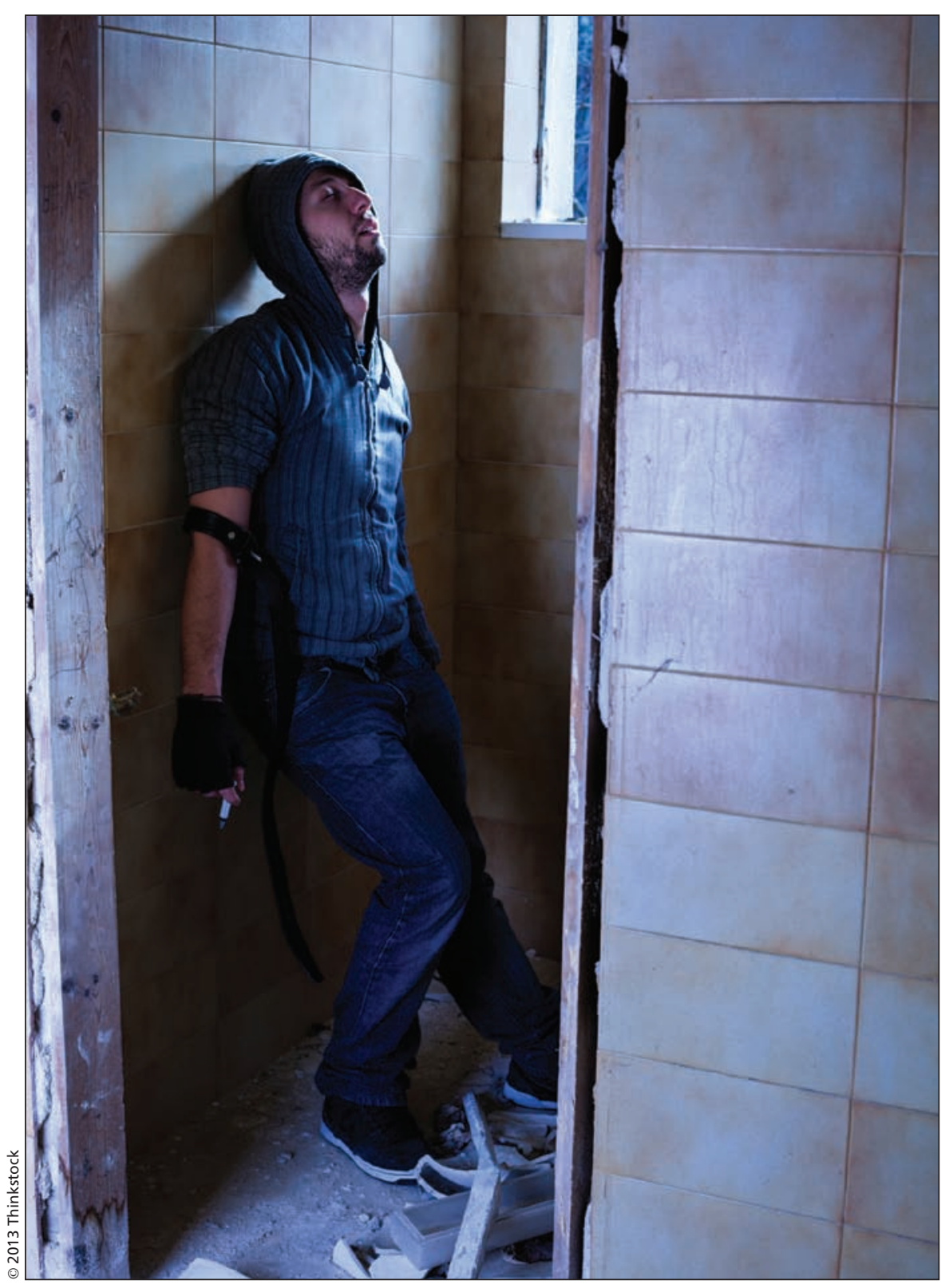

The original OxyContin, which was relatively easy to snort or inject, was widely abused.

"The Americans have chosen to ban it outright and allow the more costly version of OxyNEO to be sold. We've heard from patients that that doesn't work for them as well. And so we're all trying to deal with the issue."

Aglukkaq made the controversial decision to approve the manufacture of generic forms of oxycodone last November, despite urgings from every provincial and territorial health minister to, at the very least, delay the decision until more research had been conducted.

The federal government's decision not to revisit the approval is not sitting 
well with the Ontario minister of health and a prescription drug abuse expert.

"I think the science supports the banning of [the generic version]," says Ontario Health Minister Deb Matthews. "I think the evidence is absolutely clear that oxycodone addiction is a very, very serious problem throughout Canada ... and I applaud [the FDA's] decision."

She says the FDA likely looked at the complete profile of the drug including its safety and whether people use it as prescribed. "And that's the perspective I wished the Canadian federal government had taken."

Matthews said she will continue to urge Health Canada to reconsider its decision. At a recent meeting of Canadian health ministers, the issue arose spontaneously "and people feel as passionately now as they did [in November]. And the greatest passion comes from the health ministers in the territories."
Dr. Irfan Dhalla, a member of the national advisory council that recently released a strategy for prescription drug abuse and misuse and a physician at St. Michael's Hospital in Toronto, Ontario, agrees with Matthews.

"The FDA made the right call. I can't understand why Health Canada wouldn't want to look at the evidence the FDA reviewed and reconsider," Dhalla writes in an email. "The FDA is signaling, both through its decision and through its admirably transparent communications, that it wants all opioids to be tamper-resistant in the near future. Health Canada should be moving in the same direction."

Instead, Health Canada is touting its decision to approve generic oxycodone as a success, just four months after the decision was made.

Outhouse says although it's still early in the process, there are positive indicators that it's not been prescribed as often as it has been in the past.

"It's down to very low levels which seems to ... back up the minister's position. ... [It] makes it available for people who need it ... to access it legally and to ... pay a better price than they would if they had to go through brand name options."

Dhalla thinks it's too early to assess the health effects of allowing generic oxycodone onto the market in Canada.

"Fortunately, I think the vast majority of physicians are not prescribing generic OxyContin. But some probably are, and I think it's highly likely that some people will probably die as a result. Health Canada should have made the right decision last year. But better late than never." - Adam Miller, CMAJ

CMAJ 2013. DOI:10.1503/cmaj.109-4476 